\title{
Low Birthweight Infants in Twin Gestation
}

\author{
Alphonsus N. Onyiriuka \\ Dept of Child Health \\ Benin City, Nigeria
}

\begin{abstract}
Aim: To determine the incidence and document some of the characteristics of low birth weight (LBW) twin neonates.

Methods: A descriptive analysis of data on 119 LBW twins delivered between 1st January, 2000 and 31 st December, 2003 in a Nigerian Mission Hospital in Benin City was carried out. The characteristics of the LBW twins were studied in relation to perinatal mortality.

Results: The overall incidence of LBW twin was $51.7 \%$ with a female preponderance. Of the 107 live-born LBW twins, 74 (69.2\%) compared to 33 (30.8\%) were preterm and term small-for-gestational age (SGA) births respectively $(p<0.001)$. Twenty six $(35.1 \%)$ of the 74 preterms were very preterm ( $<32$ weeks gestation), corresponding to $24.3 \%$ of all LBW twins. The associated perinatal mortality for the two categories of LBW neonates were $21.6 \%$ for preterm and 9.1\% for term SGA neonates ( $p>0.05)$. Of the 119 LBW twins, 7.6\% were extremely LBW, $10.1 \%$ very LBW while $57.1 \%$ were in $2000-2499 \mathrm{~g}$ category. Fifty one (42.9\%) of LBW twin weighed less than $2000 \mathrm{~g}$. The risk of delivery of LBW twin was significantly higher in primiparous women $(p<0.001)$, as well as in mothers who were unbooked $(p<0.001)$ or lacked formal education $(p<0.01)$. Out of 9 growth discordant LBW twins, 6 (66.7\%) had birthweight difference $\geq 30 \%$.
\end{abstract}

Conclusion: In twin gestations, preterm delivery is a more important contributor to LBW than term SGA delivery with majority of these preterm births were delivered by primiparous mothers.

Keywords: Twins, low birthweight, primiparity, growth discordance.

\section{Introduction}

In both developing and developed countries low birthweight (LBW) infants are at increased risk of perinatal morbidity and mortality, with the risk being higher in the former. ${ }^{1-4}$ Ashworth et al reported that a fall in incidence of LBW infant from 30 to 15 percent resulted in a drop in infant mortality by 25 percent. $^{5}$ Thus, emphasizing the importance of strengthening strategies for prevention of LBW in developing countries, where the incidence is higher and the facilities for their care are often lacking. ${ }^{6}$

Twin gestation is an important cause of LBW in Nigeria. ${ }^{7}$ The reported incidence of LBW twin was $55.1 \%$ in Lagos and $49.8 \%$ in Afikpo. ${ }^{8,9}$ Incidence of LBW in twin gestations has been shown to change with time. For instance, at the University of Ilorin
Teaching Hospital, the reported incidence of LBW twin infant was $46 \%$ in $1986^{10}$ but rose to $64.3 \%$ in $1993 .{ }^{11}$ Whether the incidence has risen further, or has fallen, is not known with certainty. Data on baseline incidence and characteristics of LBW twin are therefore needed to define the current magnitude of the problem and plan strategies for prevention. Even in developed countries the documented incidence of LBW twin infants is as high as 50 to 60 percent, a figure that is five to seven times higher than the incidence of LBW in singletons. ${ }^{12}$

As part of Millennium Development Goals, effort to reduce infant mortality rate in Nigeria must include strategies for reducing incidence of LBW infants. Given the high incidence $(33-53$ per thousand deliveries) of twin gestation in Nigeria and its

Correspondence

Dr Alphonsus N. Onyiriuka, MBBS; FMCPaed

Dept of Child Health

University of Benin of Teaching Hospital

Pmb 1111, Benin City, Nigeria

Mobile : +2348032529437

Email: alpndiony@yahoo.com; didiruka@gmail.com 
significant contribution to the incidence of LBW in our society, planning of appropriate intervention programme for reduction of incidence of LBW must take into consideration strategies for reducing prevalence of LBW twin infants. ${ }^{7,13,14}$ This can only be achieved if a current baseline data on the incidence and the socio-demographic risk factors for delivery of LBW twins are available.

The present study, therefore, sought to document the baseline incidence of LBW twin infants in Benin City and some of the characteristics of the infants and their mothers.

\section{Methods}

This cross-sectional study was conducted at $\mathrm{St}$ Philomena Catholic Hospital (SPCH), Benin City, Nigeria between 1st January, 2000 and 31st December, 2003. During the study period, all twin babies delivered at SPCH were weighed naked, within the first 30 minutes after birth, by a trained midwife using a mechanical Waymaster weighing scale calibrated to the nearest 50 grammes. The scale was periodically standardized with known weights for reliability and checked daily for zero error to ensure accuracy. The birth order, weights, sexes and Apgar scores of the infants were recorded according to the month and year of delivery. Gestational age was determined from the maternal dates and Dubowitz Scores, obtained 12 to 24 hours after birth. ${ }^{15}$ Where a discrepancy of more than two weeks was observed, the gestational age was assigned from the Dubowitz score. The medical records of these mothers were examined for antenatal care registrations and attendance, maternal age, parity, occupation and educational attainment. The social class of the women were determined by combining a woman's educational attainment with her husband's occupation as suggested by Olusanya et al. ${ }^{16}$ In this Social Classification System, social classes I and II, social class III and social classes IV and $\mathrm{V}$ represent high, middle and low social classes respectively.

In this study, the following definitions were used: Discordance was defined as a difference in weight of $20 \%$ or more and was calculated as a percentage of the birthweight of the heavier twin [discordance (\%) $=100$ (birthweight difference /birthweight of heavier twin]. Twin pairs were designated discordant-first or discordant-second depending on whether the smaller one was first- or second-born respectively. A smallfor-gestational age infant was one whose birthweight was less than the tenth percentile for twins according to Cohen et al criteria. ${ }^{17}$ A low birthweight (LBW) infant was one whose birthweight was less than $2500 \mathrm{~g}$, regardless of gestational age. ${ }^{18}$ An infant who was delivered before 37 completed weeks of gestation was accepted as preterm. ${ }^{19}$ Chi square test and Z-test were used to ascertain the level of significance of differences, which was set at $\mathrm{p}<0.05$.

\section{Results}

Of the 4,544 deliveries during the 4-year study period, $115(2.5 \%)$ were sets of twins, resulting in 230 babies of which $119(51.7 \%)$ were low birthweight (LBW) with a male to female ratio of $0.78: 1$. Twin gestation accounted for $31.2 \%$ of all LBW infants delivered in the hospital. Out of the 119 LBW twin infants, 12(10.1\%) were stillborn, leaving 107 as live-born. LBW infants accounted for $85.7 \%$ of all stillbirths among twins. The 12 stillbirths comprised of $9(75 \%)$ fresh and 3(25\%) macerated stillbirths of which $5(41.7 \%)$ and $7(58.3 \%)$ were males and females respectively (M:F $=0.7: 1)$. Distribution of sex-pair in LBW twin infants was as follows: (i) different sex 20(33.9\%); (ii) same-sex male 14(23.7\%); and (iii) same-sex female 25(42.4\%), giving a ratio of 1.4:1:1.8. In one twin pair (both females), the first-born weighed more than $2500 \mathrm{~g}$ at birth while the second-born was a LBW infant. Comparing the incidence of delivery of LBW twin infants in the dry and wet seasons, it was $2.1 \%$ versus $1.8 \%$, corresponding to $52.1 \%$ and $47.9 \%$ of all LBW twin infants respectively $(\mathrm{p}<0.05)$.

The incidence of delivery of LBW twin infants according to maternal age and parity is summarized in Table I. There was no significant difference in incidence of delivery of LBW twins in relation to maternal age. Comparing primiparous with multiparous women, the risk of delivery of LBW twin infant was significantly higher in the former $(p<0.001)$. Similarly, grand multiparous women also showed significantly higher risk than their multiparous counterparts $(\mathrm{p}<0.01)$. Table I also showed that lack of formal education and unbooked status in the mother were significant risk factors for delivery of LBW twin infants $(p<0.001)$. Table II summarizes the number of cases seen in each birthweight category. Mean birthweight of the study population was $1968 \mathrm{~g}$ (95\% Confidence Interval, CI $=1889-2047 \mathrm{~g}$ ). Seventy four (69.2\%) of all live-born LBW twins were preterm rather than term SGA infants 33(30.8\%) Z-statistic $=3.974 p<0.001$; Distribution of the 74 preterm LBW twin infants according to maternal parity was as follows: (i) primiparous 50(67.6\%); (ii) multiparous $8(10.8 \%)$; and (iii) grand multiparous $16(21.6 \%)$; primiparous versus multiparous women: $\mathrm{Z}$-statistic $=3.529 \mathrm{p}<0.001$. Grand multiparous versus multiparous women: $Z$-statistic $=0.714 \mathrm{p}>$ 0.05 ; Figure 2. With regard to perinatal deaths, no significant difference between male and female LBW twin infants $(\mathrm{p}>0.05)$. Perinatal mortality rate (PMR) was $21.6 \%$ in preterms, corresponding to $84.2 \%$ of all perinatal deaths among LBW twin infants. Comparing very preterm (gestational age 28-32 weeks) infants 
with their counterparts with gestational age of 33-36 weeks, PMR was significantly higher in the former $(p<0.001)$. The incidence of birth asphyxia was $15.0 \%$ among LBW twin infants compared to an overall incidence of $8.4 \%$ in the same institution during the study period. Out of a total of 107 live-born twin pairs, $19(17.8 \%)$ had birth weight difference $\geq 20 \%$ with the degree of growth discordance being $35 \%$ or more in $33.3 \%$ of cases. Of the nine discordant LBW twin infants, 5(55.6\%) and 4(44.4\%) were discordant-first and discordant-second twin respectively. Distribution by sex-pair with regard to discordant growth was as follows: (i) different sex 3(33.3\%); (ii) same-sex female 4(44.4\%); and same-sex male 2(22.3\%), corresponding to a ratio of $1.5: 2: 1$.

Out of 49 live-born LBW twin pairs, 9(18.8\%) demonstrated birthweight difference greater than $25 \%$ with 6 of the $9(66.7 \%)$ cases having extreme degree of intrapair growth discordance (birthweight difference $\geq 30 \%$ ).

\section{Table 1. Incidence of LBW and maternal characteristics}

\begin{tabular}{|c|c|c|}
\hline Maternal characteristics & $\begin{array}{c}\text { Total delivery } \\
\text { No (\%) }\end{array}$ & $\begin{array}{c}\text { LBW Twin infants } \\
\text { No. (\%) }\end{array}$ \\
\hline \multicolumn{3}{|l|}{ Age (years) } \\
\hline$\leq 19 \mathrm{a}$ & $109(2.4)$ & $5(4.2)$ \\
\hline $20-34 b$ & $3742(82.4)$ & $90(75.6)$ \\
\hline$\geq 35 \mathrm{c}$ & $668(14.7)$ & $22(18.5)$ \\
\hline Unknown & $25(0.5)$ & $2(1.7)$ \\
\hline Total & $4544(100)$ & $119(100)$ \\
\hline \multicolumn{3}{|l|}{ Parity } \\
\hline $0 \mathrm{~d}$ & $1478(32.5)$ & $74(62.2)$ \\
\hline $1-4 \mathrm{e}$ & $2605(57.3)$ & $17(14.3)$ \\
\hline$\geq 5 \mathrm{f}$ & $461(10.2)$ & $28(23.5)$ \\
\hline Total & $4544(100)$ & $119(100)$ \\
\hline \multicolumn{3}{|l|}{ Educational level } \\
\hline No schoolingg & $539(11.7)$ & $55(46.2)$ \\
\hline Primary & $1360(29.9)$ & $35(29.4)$ \\
\hline Secondary h & $2067(45.5)$ & $24(20.2)$ \\
\hline Post - secondary & $586(12.9)$ & $5(4.2)$ \\
\hline Total & $4544(100)$ & $119(100)$ \\
\hline \multicolumn{3}{|l|}{ Social class } \\
\hline I & $383(8.4)$ & $8(6.7)$ \\
\hline II & $527(11.6)$ & $13(10.9)$ \\
\hline III & $1149(25.3)$ & $20(16.8)$ \\
\hline IV & $1500(33.0)$ & $31(26.1)$ \\
\hline $\mathrm{V}$ & $985(21.7)$ & $47(39.5)$ \\
\hline Total & $4544(100)$ & $119(100)$ \\
\hline \multicolumn{3}{|l|}{ Booking status of mothers } \\
\hline Bookedk & $3508(77.2)$ & $69(58.0)$ \\
\hline Unbookedl & $1036(22.8)$ & $50(42.0)$ \\
\hline Total & $4544(100)$ & $119(100)$ \\
\hline
\end{tabular}

a versus $b: x 2=2.096 p>0.05$

$\mathrm{d}$ versus e $\mathrm{x} 2=30.272 \mathrm{p}<0.0001$

e versus $f \times 2=9.360 p>0.05$

$\mathrm{g}$ versus $\mathrm{h} \times 2=11.893 \mathrm{p}<0.05$

$\mathrm{k}$ versus $1 \times 2=23.972 \mathrm{p}<0.001$

High versus low social class $\mathrm{x} 2=1.539 \mathrm{p}>0.05$ 
Table 2. Characteristics of LBW twin infants and related perinatal deaths.

\begin{tabular}{|c|c|c|}
\hline Characteristics of LBW twin & $\begin{array}{c}\text { LBW twin } \\
\text { No (\%) }\end{array}$ & $\begin{array}{c}\text { Perinatal deaths } \\
\text { No }(\%)\end{array}$ \\
\hline \multicolumn{3}{|l|}{ Birth-weight } \\
\hline \multicolumn{3}{|l|}{ categories (g) } \\
\hline$<1000$ & $9(7.6)$ & $9(100)$ \\
\hline $1000-1499$ & $12(10.1)$ & $10(83.3)$ \\
\hline $1500-1999$ & $30(25.2)$ & $9(30.0)$ \\
\hline $2000-2499$ & $68(57.1)$ & $3(4.4)$ \\
\hline Total & $119(100)$ & $31(26.1)$ \\
\hline \multicolumn{3}{|l|}{ Birth order } \\
\hline First - born twina & $56(47.1)$ & $13(23.2)$ \\
\hline Second - born twinb & $63(52.9)$ & $18(28.6)$ \\
\hline Total & $119(100)$ & $31(26.1)$ \\
\hline \multicolumn{3}{|l|}{ Sex } \\
\hline Malec & $52(43.7)$ & $17(33.0)$ \\
\hline Femaled & $67(56.3)$ & $14(20.9)$ \\
\hline Total & $119(100)$ & $31(26.1)$ \\
\hline Type of LBW (live - born) & & Neonatal deaths No (\%) \\
\hline Preterme & $74(69.2)$ & $16(21.6)$ \\
\hline Term SGAf & $33(30.8)$ & $3(9.1)$ \\
\hline Total & $107(100)$ & $19(17.8)$ \\
\hline \multicolumn{3}{|l|}{ Gestational age weeks (live - born) } \\
\hline $28-32 \mathrm{~g}$ & $26(24.3)$ & $14(53.8)$ \\
\hline $33-36 h$ & $47(43.9)$ & $4(8.5)$ \\
\hline$\geq 37$ & $34(31.8)$ & $1(2.9)$ \\
\hline Total & $107(100)$ & $19(17.8)$ \\
\hline \multicolumn{3}{|l|}{ Birth asphyxia (live-born) } \\
\hline Yes & $16(15.0)$ & $6(37.5)$ \\
\hline No & $91(85.0)$ & $13(14.3)$ \\
\hline Total & $107(100)$ & $19(17.8)$ \\
\hline
\end{tabular}

a versus $b \times 2=0.442 p>0.05$

$c$ versus $d \times 2=2.115 p>0.05$

e versus $f \times 2=3.635 p>0.05$

g versus $h \times 2=18.520 p<0.01$

Table 3. Birthweight discordance in LBW twin

\begin{tabular}{cccccc}
\hline $\begin{array}{c}\text { Twin I } \\
\text { birth- weight (g) }\end{array}$ & Sex & $\begin{array}{c}\text { Twin II } \\
\text { birth- weight (g) }\end{array}$ & Sex & $\begin{array}{c}\text { Birth-weight } \\
\text { difference(g) }\end{array}$ & $\begin{array}{c}\text { Level of } \\
\text { discordance (\%) }\end{array}$ \\
\hline 1650 & F & 2350 & F & 700 & 29.8 \\
1100 & F & 1500 & F & 400 & 26.7 \\
1800 & F & 1200 & F & 600 & 33.3 \\
1800 & F & 2450 & F & 650 & 26.5 \\
1600 & F & 2400 & M & 800 & 33.3 \\
500 & M & 1250 & M & 750 & 60.0 \\
1500 & M & 1000 & M & 500 & 33.3 \\
2050 & F & 1300 & M & 750 & 36.6 \\
1300 & F & 2000 & M & 700 & 35.0 \\
\hline
\end{tabular}

Twin $\mathrm{I}=$ first-born twin

Twin II = second-born twin 


\section{Discussion}

The $51.7 \%$ overall incidence of delivery of LBW infant in twin gestations reported here is close to $49.8 \%$ reported from another mission hospital in Afikpo but lower than $63.4 \%$ and $55.1 \%$ reportedly previously from two Nigerian teaching hospitals in Ilorin and Lagos respectively. ${ }^{8,11}$ On the other hand, it was higher than $43.4 \%$ reported from Boston, USA. ${ }^{19}$ The lower incidence found in the present study may be accounted for by the fact that data from Ilorin and Lagos were derived from teaching hospitals. Traditionally, teaching hospitals are referral centres, therefore more cases of pregnancies associated with intrauterine growth restricting factors are more likely to be referred to them, resulting in higher incidence. Such referralbias is known to increase the incidence of medical conditions. ${ }^{20}$ The lower incidence reported from Boston, USA, may be due to better maternal nutrition and utilization of antenatal care services. This view was supported by the significantly higher incidence of delivery of LBW twin infants among unbooked mothers compared to their booked counterparts in the present study.

Our data indicated that maternal parity have a significant influence on the incidence of delivery of LBW infants in twin gestations. As in previous studies, the incidence was higher in primiparous compared with their multiparous counterparts, suggesting that the uteri of multiparous women are more efficient in nurturing and promoting intrauterine growth of twins; accounting for the relatively lower incidence of LBW twin infants among them. ${ }^{10,11,21}$

Teenage twin mothers demonstrated an increased risk of delivery of LBW infants. A similar finding has been reported from Ilorin. ${ }^{11}$ Teenage twin mothers may not have the necessary financial and emotional support from their spouses, and so, were less likely to utilize and benefit maximally from available maternal health care services. This was supported by the adverse effect of maternal unbooked status on birthweight reported in this study.

In twin gestations, prematurity is a more important contributor to delivery of LBW infant than term SGA. This finding strongly challenges the report of some studies which stated that majority of LBW infants in developing countries were due to term SGA rather than preterm delivery. ${ }^{22,23}$ The risk of perinatal death was higher in very preterm infants, suggesting that there is a need to make effort to prolong gestation beyond 32 weeks. One way of achieving this, is by instituting a prophylactic hospitalization policy (bed rest) for all women with twin pregnancy between 28 and 32 weeks gestation. The usefulness of such an approach has been reported by Younis et al. ${ }^{24}$
Although the number was small, LBW twin pairs tended to demonstrate extreme degree of intrapair growth discordant (birthweight difference $\geq 30 \%$ ). In the present study, this was the case in $62.5 \%$ of all cases of discordant LBW twin infants. An explanation for this finding may be found in the report of Blackstein et al which stated that low combined twin pair birthweight was associated with extreme levels of intrapair growth discordance. ${ }^{25}$ Some investigators have shown that the perinatal risks from birthweight discordance were greater when the infants were LBW compared to when they were of normal birthweight, further emphasizing the need to evaluate every LBW twin pair for growth discordance to improve perinatal health. ${ }^{26,27}$

\section{Conclusion}

In twin gestations, preterm delivery is a more important contributor to LBW than term SGA delivery with majority of these preterm infants delivered by primiparous mothers.

\section{References}

1. Ghosh S, Bhargava SK, Saxena HMK, Sagreiya K. Perinatal mortality: report of a hospital-based study. Ann Trop Paediatr 1983; 3: 115 - 119.

2. Barros FC, Victoria CG, Vanghan JP, Estanislau HJ. Perinatal mortality in Southern Brazil: a population - based study of 7,392 births. Bull Wld Hlth Org 1978; 65: 95 - 104.

3. Thilo EH, Rosenberg AA. The newborn infant. In: Hay WW Jnr, Levin MJ, Sondheimer JM, Deterding RR (eds). Current Diagnosis and Treatment in Pediatrics. $18^{\text {th }}$ edition. New York McGraw-Hill Companies 2007; 1-64.

4. Darmstadt GL, Lawn JE, Costello A. Advancing the State of the world's newborns. Bull Wld Hlth Org 2003; 81 (3): $224-225$.

5. Ashworth A, Feachem RG. Interventions for the control of diarrhoeal diseases among young children: prevention of low birth weight. Bull Wld Hlth Org 1985; 63: $165-184$.

6. Chan M. Low birth weight infants. In: Stanfield P, Brueton M, Chan M, Parkin M, Waterston T (eds). Diseases of Children in Subtropics and Tropics $4^{\text {th }}$ edition. London: Arnold Publishers Ltd 1991; $208-220$.

7. Onyiriuka AN. Trends in incidence of delivery of low birth weight infants in Benin City, Southern Nigeria. Nig Postgrad Med J 2006; 13 (3) : 189 $-194$.

8. Ekure EN, Iroha EO. Perintal mortality among twins in Lagos University Teaching Hospital: Associated risk factors. Nig Qtr J Hosp Med 2002; 12: 21-25.

9. Sunday - Adeoye I, Twomey ED, Egwuatu VE. A 20-year review of twin births at Mater 
Misericordiae Hospital, Afikpo, South Eastern Nigeria. Nig J Clin Pract 2008; 11 (3): 231 $-234$.

10. Fakeye O. Twin birth weight in Nigeria and the effect of sex-pair and parity. Trop Geogr Med 1986; 38: $265-270$.

11. Oyewoye OA, Fakeye O. Twin low birth weight infants in Nigeria: prevalence, types and prevention strategies. Nig Med Pract 1993; 26: $18-20$.

12. Mc Culloch K. Neonatal problems in twins. Clin Perinatol 1988; 15: $141-158$.

13. Omu AE. Multifetal pregnancy In: Okpere EE (ed). Clinical Obstetrics. Benin City: Uniben Press (publishers) 2003; $180-188$.

14. Omu AE, Akingba JB. Contrtibution of multiple pregnancy to perinatal mortality in Benin City. Trop J Obstet Gynaecol 1983; 3: 227 - 232.

15. Dubowitz LMS, Dubowitz V, Goldberg C. Clinical assessment of gestational age of the newborn infant. J Pediatr 19701; 77: 1 - 10.

16. Olusasnya O, Okpere E, Ezimohkai M. The importance of social class in voluntary fertility control in a developing country. West Afr J Med 1985; 4: $205-211$.

17. Cohen SB, Mordechai D, Liptz S, Mashiach S, Schiff E. New birth weight normograms for twin gestation on the basis of accurate gestational age. Am J Obstet Gynecol 1997; 177: 1101 - 1104.

18. World Health Organisation Expert Committee. Physical Status: The use and Interpretation of Anthropometry. WHO Techn Report Series, Geneva 1995; 854: 161 - 262.

19. Friedmann EA, Sachtleben MR, Friedmann LM.
Relative birth weight of twins. Obstet Gynecol 1997; 49: 717 - 720 .

20. Grimes DA, Schulz KF. Bias and causal associations in observational research. Lancet 2002; 359: 248 - 252 .

21. Blickstein I, Zalel Y, Weissman A. Pregnancy order: A factor influencing birthweight in twin gestations. J Reprod Med 1995; 40: 443-446.

22. Yasmin S, Osrim D, Paul E, Costello A. Neonatal mortality of low birth weight infants in Bangladesh. Bull Wld Hlth Org 2001; 79 (7): $608-614$.

23. Villar J, Belizan J. The relative contribution of prematurity and fetal growth retardation to low birth weight in developing and developed countries. Am J Obstet Gynecol 1982; 143: 793 $-798$.

24. Younis JS, Sadovsky E, Eldar-Geva T, Mildwidsky A, Zeevi D, Zajicek G. Twin gestations and prophylactic hospitalization. Int J Gynecol Obstet 1990; 32: 325 - 330 .

25. Blickstein I, Goldman RD, Smith-0Levitin M, Greenberg M, Sherman D, Rydhstroem H. The relation between inter-twin birthweight discordance and total twin birthweight. Obstet Gynecol 1999; 93: 113-116.

26. Cheung VY, Bocking AD, DaSilva OP. Preterm discordant twins: what birth weight difference is significant? Am J Obstet Gynecol 1995; 172: 955-999.

27. Blickstein I, Goldman RD, Mazkereth R. Adaptive growth restriction as a pattern of birth weight discordance in twin gestations. Obstet Gynecol 2000; 96: 986-989. 